\title{
Estilos de vida de imigrantes e refugiados nos meios de comunicação
}

\author{
Alexandre Marcelo Bueno ${ }^{a}$
}

\begin{abstract}
Resumo
Dentre as reportagens sobre a imigração contemporânea para o Brasil, podemos distinguir diferentes grupos estrangeiros a partir do trabalho que eles realizam: um que mostra os chamados trabalhadores estrangeiros "qualificados" que chegam para ocupar postos de direção em multinacionais; outro que se refere aos que trabalham no comércio, administrando seus próprios negócios; um terceiro que apresenta os imigrantes "sem qualificação"; e, por fim, um último que pode ser encarado como o "artista". Se partimos da premissa de que o papel temático do imigrante é o de um sujeito do trabalho, observamos como esses sentidos ligados ao universo do trabalho são sobredeterminados por outros que misturam classe social e origem nacional. Além dessas questões, desejamos observar como essa divisão dos grupos é valorada positiva e negativamente como uma forma de tentar entender como a sociedade brasileira sanciona os diferentes grupos imigrantes e suas diferentes funções sociais no trabalho. Por fim, veremos ainda como são construídas as imagens do país, um tópico recorrente nessas reportagens. Para alcançar nossos objetivos, recorremos aos postulados da semiótica discursiva, em especial às propostas da sociossemiótica.
\end{abstract}

Palavras-chave: Estilos de vida. Imigração. Sanção. Valores. 
${ }^{1}$ Em semiótica, o ator do discursoéo encontro das estruturas narrativas $\mathrm{ma}$ is abstratas, constituídas por papeis actanciais (destinador, destinatário, sujeito e objeto), com o papel temático (pai, rei, pescador, contador, empresário, trabalhador etc.) que se localiza no nível discursivo. Quando ocorre a operação de figurativização, esse elemento ainda abstrato obtém uma significação mais concreta, ou seja, próxima da ideia de elementos perceptíveis no mundo natural. É justamente na passagem entre um nível mais abstrato a um outro mais concreto que centramos o desenvolvimento de nossa análise para chegarmos a uma tipologia dos estilos de vida dos imigrantes nos meios de comunicação. Para um maior esclarecimento, remetemos à leitura de Greimas \& Courtès (2008, pp. 44-45).

\section{Introdução}

Quando pensamos na imigração contemporânea para o Brasil, uma série de imagens surge, sobretudo porque são veiculadas pelos meios de comunicação com certa frequência: a exploração dos imigrantes em oficinas de costura (muitas vezes em uma situação análoga à escravidão), a precariedade em que vivem, as dificuldades encontradas no país, seja por aspectos linguísticos ou jurídicos, como a regularização de sua situação no país, certas "curiosidades" sobre sua culinária, religião ou tradições. No entanto, ao lado dessas representações, há outras mais raras que são também manifestadas por discursos veiculados pela mídia tradicional (como a impressa ou a televisiva) ou pelas novas plataformas digitais, como blogs.

Para examinarmos essas significações, é preciso ultrapassar os discursos realizados e materializados em sua unicidade, a partir da articulação promovida por cada enunciador que transforma a presença dessa alteridade em um ator ${ }^{1}$ de seu discurso. É por isso que optamos por selecionar desde reportagens da mídia impressa até blogs, assim como discursos predominantemente verbais até linguagens sincréticas, como o noticiário televisivo encontrado na internet. Entendemos que a coerência necessária para articular a significação que desejamos demonstrar, nesse caso em particular, não se encontra na manutenção de um único gênero, no tipo textual ou mesmo em uma única notícia. A coerência a que visamos estará assentada, principalmente, no modo como a sociedade, por meio desses diferentes enunciados, revela variados simulacros do Outro, a depender de algumas características da alteridade de que seus discursos estão tratando.

No universo relativamente amplo de discursos sobre a imigração e o refúgio no Brasil, observamos distintos olhares sobre esses sujeitos, principalmente se o ato de diferenciar algumas alteridades de outras revela valores que estabelecem uma hierarquia entre esses sujeitos. Esse foi o caso do título de uma notícia que começou a nos chamar a atenção para a questão sobre a nomeação do trabalhador imigrante: " $94,6 \%$ dos vistos de trabalho são para estrangeiros qualificados, diz governo" (KOMETANI, 2013). 
${ }^{2}$ Eric Landowski é, no campo da semiótica discursiva, o autor que mais reflete sobre a dimensão social da significação. No referido trabalho, ele propõe uma tipologia das interações sociais que envolvem as relações entre identidade e alteridade: a a ssimilação, a exclusão, a segregação e a admissão. O próprio autor, na mesma obra, mostra como a alteridade também utiliza esses conceitos como orientadores da relação com a identidade. Uma das vantagens de sua proposta é a de abrir o caminho para examinar como a identidade constrói as imagens da alteridade e, com isso, pensar em como alguns grupos são mais ou menos valorizados.
Esse título foi responsável por algumas inquietações que orientaram nossa análise: qual ou quais os traços que definem a "qualificação" maior ou menor de um imigrante em relação ao trabalho? De que maneira essa "qualificação" (ou sua falta) orienta a construção das diferentes imagens dos imigrantes e de suas relações com a sociedade brasileira? E, por fim, quais as consequências, para a dinâmica social da significação, que tal hierarquização produz e revela em termos de valores apreciados ou desvalorizados pela sociedade brasileira?

São esses os pontos principais que conduzirão o presente trabalho até uma resposta, que esperamos seja adequada às questões postas. De qualquer maneira, partimos do seguinte princípio apontado por Landowski²: as imagens construídas dos imigrantes e dos refugiados são apenas uma das facetas possíveis que cada enunciador decide destacar. Assim, antes de pensarmos que as notícias determinam a "última palavra" sobre a imagem de cada um dos sujeitos e grupos imigrantes, devemos observar que cada discurso constrói apenas simulacros da alteridade:

É impossível escapar a esses rótulos; e, no entanto, eles só correspondem a uma maneira possível - a mais amplamente difundida, talvez, e, contudo, toda contingente - de construir o simulacro do outro (e, se for o caso, aquele no qual reconhecer-se a si mesmo, se não houver outro jeito) (LANDOWSKI, 2002, p. 33).

É por meio desses simulacros que desejamos articular a noção de estilos de vida como base para compreender como as sanções são aplicadas a cada forma de alteridade. Desse modo, esperamos indicar também um caminho para compreender os valores que a sociedade brasileira mais deseja ou mais teme para si mesma, refletidos nos estilos de vida dos imigrantes e dos refugiados.

Iniciaremos, então, nossa análise a partir da reportagem já mencionada. A razão para isso reside no fato de ser justamente essa reportagem uma espécie de paradigma do imigrante desejado pela sociedade brasileira, tanto pelo que ele possui, supostamente, de qualidades para o trabalho como para o comportamento social que ele pode trazer para o centro da sociedade. 


\section{O imigrante qualificado: uma alteridade valorizada}

A reportagem anteriormente citada constrói o perfil de três estrangeiros que estão no Brasil a trabalho e ocupam diferentes posições em empresas nacionais. Começamos com a transcrição de trechos da reportagem para observamos como o discurso constrói a imagem desses sujeitos. O primeiro, um trabalhador japonês, é representado da seguinte maneira:

Com formação em ciências políticas e MBA na área de negócios, o executivo japonês Seigo Ishimaru, de 45 anos, chegou ao Brasil há nove meses para trabalhar no escritório em São Paulo da Tokio Marine Seguradora. Ishimaru ainda encontra dificuldades para falar português, mas já se acostumou com a vida em São Paulo. "As pessoas são muito amigáveis e abertas aos estrangeiros", diz. Funcionário da empresa desde 1990, o executivo já acumulou passagens por Cingapura e Nova York. Agora, ele tem o desafio de fortalecer a atuação da empresa no Brasil. "Eu gosto de desafios e de trabalhar em países diferentes", afirma. O executivo levou três meses para conseguir a permissão do governo brasileiro para trabalhar no país. Para ele, o trâmite não foi tão demorado. $\mathrm{O}$ visto tem validade de dois anos amarrado ao contrato de trabalho (KOMETANI, 2013).

O segundo sujeito é um italiano. Ele possui características semelhantes ao anterior, sobretudo em relação ao seu perfil profissional:

O italiano Mario Ponticelli, de 50 anos, chegou ao Brasil há três anos para trabalhar. Na época, o visto levou quatro meses para sair. "Demorou um pouco, mas não foi nada dramático, já que precisamos entregar toda a documentação corretamente." Ponticelli chegou ao país por meio da Amadeus, empresa de soluções de tecnologia voltadas para o mercado de turismo e viagens. Com nível superior em turismo e economia, o italiano tinha uma agência de viagens em Portugal, quando foi convidado para ocupar uma vaga na Amadeus para melhorar a relação da empresa com o mercado português. Ponticelli recebeu o convite em novembro de 2009 , mas só começou a trabalhar em março do ano seguinte devido aos trâmites para a obtenção do visto. Agora, o plano do executivo é continuar no país. "Já tenho uma pátria e ela é o Brasil. Só gostaria de morar no Rio de Janeiro", diz o italiano (KOMETANI, 2013).

Por fim, a reportagem destaca um trabalhador de nível técnico, ou seja, que não possui uma graduação ou 
${ }^{3} \mathrm{O}$ sujeito, como uma posição da narrativa, é constituído por $\mathrm{d}$ e $\mathrm{t}$ e $\mathrm{rm}$ i n a d a s c o n fig u r a ç õ es modais que lhe dão a competência necessária para realizar um fazer dentro do esquema narrativo que, resumidamente, se refere a uma transformação desse sujeito em sua relação com um determinado objeto de valor. No caso, os sujeitos ao qual estamos nos referindo possuem as modalidades adequadas para a execução da ação ao qual eles estão programados para realizar. uma especialização, mas um diploma equivalente ao nosso ensino técnico:

É o caso do mexicano Raúl Ramírez, de 38 anos. Com nível técnico em informática e programação, ele foi contratado há um ano e meio pela Lumis Tecnologia, empresa de plataformas de portal, gestão de conteúdo e colaboração, com sede no Rio de Janeiro, para atuar como analista de suporte. "Eles buscavam um profissional com a minha formação e que falasse espanhol para facilitar o contato com clientes do México e da Espanha", conta. O bom momento da economia brasileira e as oportunidades disponíveis para trabalhadores especializados e com alto conhecimento também ajudaram na decisão. "Peguei a lista de documentos e, como são muitas etapas que incluem até a tradução e registro em cartório, o trâmite é bastante complicado", comenta (KOMETANI, 2013).

Esses trabalhadores possuem alguns traços recorrentes, a despeito das variações figurativas de suas respectivas histórias de vida profissional. Primeiramente, todos eles reconhecem as dificuldades para obter o visto de trabalho no Brasil (tema central da reportagem). No entanto, outros elementos, mais abstratos e gerais, vão ser responsáveis pela construção da imagem desse tipo de estrangeiro, o que é uma maneira de fazermos a passagem entre as ocorrências individualizadas dos atores do discurso para a construção de uma representação mais coletiva dessa alteridade.

Assim, outro traço destacado pela reportagem é a modalidade $^{3}$ do saber-fazer. Todos os trabalhadores são representados com um saber formal que foi anteriormente sancionado por uma instituição de ensino (dois em universidades e o terceiro em uma instituição de ensino técnico). Além disso, ainda na modalidade do saber-fazer, todos apresentam uma experiência profissional sólida, tal como a desejada pelo mercado, esse destinador implicitamente tematizado no discurso da reportagem.

Ainda como uma característica comum a esses sujeitos, vemos uma organização passional bem delimitada. Eles são sujeitos ousados, que gostam de desafios e chegam para introduzir inovações em seu novo ambiente de trabalho ("Eu gosto de desafios e de trabalhar em países diferentes").

Ao lado do saber-fazer, a representação dos trabalhadores estrangeiros também envolve a modalidade do saber-ser. Nesse 
${ }_{4}$ Mesmo porque podemos especular que os locais em que vivem e trabalham são mais ou menos padronizados, segundo uma escala global, ou seja, ocidental-capitalista.

${ }_{5} \mathrm{Na}$ proposta de Landowski (2002, pp. 37-40), o homem do mundo é uma espécie de referência para a qual algumas formas da alteridade se dirigem (camaleão ou esnobe), pois é um ideal a ser alcançado, ou se afastam (dândi e urso), uma vez que não compactuam, por diferentes motivos, com essa mesma referência. A despeito da polissemia provocada pela metalinguagem utilizada pelo autor, optamos por usar outros termos, como a alteridade assimilada (esnobe), excluída (dândi), admitida ( c a m a l e ão ) o u segregada (urso). Para todas as denominações conceituais sobre os regimes de interação, ind icamos Eric Landowski. Presenças do outro. São Paulo: Perspectiva, 2002, pp. $3-29 ; 31-66)$. caso, a modalidade se desdobra nos temas da vivência anterior em outros países e de suas experiências de vida. Podemos dizer que esses trabalhadores são cidadãos globais, ou seja, sujeitos que moraram em diferentes países e contam com uma experiência de adaptação aos costumes locais ${ }^{4}$. Ao mesmo tempo, entendemos que esses sujeitos podem ser relacionados à imagem do homem do mundo, cuja definição lapidar é dada por Landowski

(...) é um indivíduo que se caracteriza essencialmente por seu senso de adequação: sabe oferecer a todo instante as marcas de uma perfeita adesão às normas do grupo ao qual pertence. Melhor: nesse quadro, ele manifesta um tal à-vontade que quase poderíamos nos perguntar se, mais do que curvar-se aos usos, não é ele, na realidade, que os inventa e que dá o tom fornecendo, por seus comportamentos, suas "boas maneiras", seu constante a-propósito no discurso e no porte, a ilustração em carne e osso (ou o exemplum imaginário) daquilo que os ideais, ou pelo menos os standards éticos e estéticos do grupo considerado são capazes de produzir de "melhor" (LANDOWSKI, 2002, p. 37).

Em outras palavras, os trabalhadores estrangeiros qualificados chegam ao país e rapidamente podem se tornar um padrão para a sociedade local. Essa passagem pode ocorrer por meio de sua estratégia de adequação ou porque eles já chegam com o simulacro de trabalhadores com um alto padrão de formação, vivência e conhecimento. É justamente esse aspecto que observamos a partir da sanção positiva da sociedade e do Estado, que os reconhecem como sujeitos qualificados para o trabalho, como podemos perceber no trecho destacado a seguir:

O governo federal vê com bons olhos a chegada desta mão de obra qualificada. "Esses profissionais são altamente qualificados e vêm ao Brasil exercer profissões nas áreas de gerência e supervisão em empresas que demandam conhecimento não disponível", diz Almeida. "Trabalhadores imigrantes qualificados podem introduzir no país novas formas para a utilização de máquinas e equipamentos, além de novas formas de gestão. Como esta mão de obra foi qualificada em contextos distintos ao nacional, ela traz conhecimentos incorporados que podem levar a avanços tecnológicos", afirma Rosane Silva Pinto de Mendonça, diretora de programa da Secretaria de Assuntos Estratégicos (SAE) da Presidência da República. "A proposta será 
${ }^{6}$ Essa é a estrutura de base para o processo de implicação, cuja definição e $\mathrm{func}$ i o n a m e $\mathrm{to}$ encontram-se em Zilberberg (2011, p. 263-264).

${ }^{7}$ Papel temático é um traço semântico e sintático que restringe a ação de um ator do discurso a um único percurso. Por exemplo, a ação de correr pode, a depender d a configuração discursiva, ser restrita ao papel temático de um corredor, pois não se espera que ele faça alguma outra ação. No caso do texto analisado, o papel temático de executivo e de técnico restringe a construção desses imigrantes a um único papel temático para o qual eles realizam suas ações. Para maiores e s c la recimentos, consultar Greimas \& Courtès (2008, p. 496). direcionada para a busca de talentos no exterior e terá o cuidado de não interferir em profissões que hoje são seguidas por brasileiros. Queremos uma política imigratória para sustentar o crescimento e gerar mais empregos para os brasileiros e não para tirar empregos", diz André Sacconato, diretor de pesquisas da BRAiN (KOMETANI, 2013).

Dessa maneira, a reportagem mostra que esse tipo de trabalhador se constitui, do ponto de vista do Estado e das empresas, como sujeitos adjuvantes que vieram para atribuir uma modalidade do saber-fazer no percurso narrativo das empresas. Eles chegam, assim, para suprir uma falta em relação às demandas das empresas e do mercado. Consequentemente, eles são sancionados como sujeitos que auxiliam no desenvolvimento econômico das empresas e, por consequência, do Brasil, em uma sanção positiva sobre seu simulacro e que pode ser resumida da seguinte maneira: se o imigrante é qualificado, então ele é bom para o país ${ }^{6}$.

Além disso, esses sujeitos possuem um papel temático ${ }^{7}$ restrito e facilmente identificável: eles são ou o executivo ou o técnico. Esse papel temático especificado pelo discurso pode também explicar o fato de eles não serem identificados como imigrantes no título, mas sim como trabalhadores estrangeiros. A operação de generalização do lexema "estrangeiro" serve, em nosso entendimento, para apagar os sentidos negativos associados à palavra "imigração" (associada aos trabalhadores explorados e com formação supostamente precária) que mantém uma relação hiponímica com o lexema "estrangeiro". Além disso, chamá-los de trabalhadores estrangeiros é como postular a existência de um universo global no qual há uma categoria profissional que prescinde de sua nacionalidade. Em outras palavras, é como se houvesse uma classe internacional de trabalhadores, mais ou menos homogênea, que estaria disponível para o mercado igualmente globalizado e dinâmico.

Técnico ou executivo, o imigrante "qualificado" possui, como mostramos, elementos invariantes em sua constituição. Esses elementos, além de definir uma certa padronização na identidade desse tipo de alteridade, ainda servem para contrapô-los ao outro tipo de imigrante que apresentaremos na próxima seção. 


\section{O imigrante não qualificado: a alteridade explorada}

Como comparação a esse imigrante considerado qualificado, podemos pensar em um imigrante diametralmente oposto. Esse é o imigrante que ocupa postos de trabalho precários, sem carteira assinada e explorado por seus patrões quando começa a trabalhar no Brasil:

Os bolivianos fazem jornadas muito acima da lei [permite até dez horas diárias], ganham centavos por peça produzida e moram no local de trabalho. São vários adultos e crianças alojados em um mesmo cômodo, muitas vezes sem ventilação, com fiação aparente oferecendo riscos", afirma a procuradora Vera Lúcia Carlos (ROLLI; FERNANDES, 2007a). "O local de trabalho se misturava ao de moradia das famílias, das crianças, sem espaço de refeição, com instalações elétricas precárias, sem condições sanitárias adequadas, sem ventilação. Faltam condições dignas de trabalho", diz Renato Bignami, chefe da fiscalização do MTE em São Paulo (ROLLI, 2010).

Bolivianos que estão irregulares no país e trabalham em condições insalubres relataram à reportagem que preferem trabalhar dessa forma a "passar fome em seu país". "Aqui pagam pouco, não tem registro em carteira. Mas é melhor do que lá", diz Juan (o nome é fictício porque teme sofrer represálias). Ele afirma cumprir jornada das $7 \mathrm{~h}$ às $22 \mathrm{~h}$, de segunda a sexta. Aos sábados, trabalha das $7 \mathrm{~h}$ às $12 \mathrm{~h}$. Recebe $\mathrm{R} \$ 0,50$ por peça costurada e envia parte do pagamento à família (ROLLI; FERNANDES, 2007b).

O imigrante "explorado" possui também algumas características em comum que o definem e o diferenciam do imigrante anterior. A primeira diferença em relação ao imigrante "qualificado" ocorre na modalidade do fazer. Ele não é construído como um sujeito do saber-fazer, pois seu trabalho supostamente não necessita de um conhecimento específico, de uma formação acadêmica. Essa questão diz muito sobre a valorização dada ao diploma universitário ou técnico, enquanto saberes associados a uma aprendizagem prática (como no fazer artesanal e/ou manual) são desconsiderados como valores a serem reconhecidos, estimulados e respeitados. Desse modo, não há qualquer menção a uma possível habilidade e competência em seu fazer, mas apenas a constatação de que esses imigrantes realizam uma ação voltada ao trabalho.

Os imigrantes explorados são, em termos passionais, construídos como sujeitos de um querer-ser ainda virtualizado, 
${ }^{8}$ No esquema narrativo, o antissujeito é a função que compete com o sujeito o predomínio de um determinado objeto devalor, ponto centralda narrativa e responsável pelas transformações que a definem conceitualmente. $\mathrm{O}$ de stin a d o r manipulador é a função narrativa responsável por levar o sujeito a realizar a ação estabelecida por meio de um contrato fiduciário, ou seja, por meio de um contrato de confiança no qual está previsto o reconhecimento e a possível premiação ao final da ação realizada. Para fazer com que o sujeito aceite o contrato, o destinadormanipulador possui algumas estratégias, como a intimidação, a tentação, a provocação e a sedução (enquanto organizações modais produzidas em torno do saber ou do poder do destinador).

${ }^{9} \mathrm{O}$ fazer programado decorre das chamadas "coerções sociais" e podem ser entendidas como regularidades que regem as práticas rotineiras. Para mais in form a ções, cf. LANDOWSKI, 2014. cujos temas são o desejo de se regularizar e de ter um trabalho decente, como visto no trecho anterior. Em outras palavras, não são sujeitos ainda realizados, no sentido de que não detêm ainda as modalizações necessárias para uma existência modal plena que permita a concretização de seus desejos (GREIMAS, 2014, p. 107).

Ainda em termos de modalidades, esses imigrantes são também construídos como sujeitos do não-poder-ser (pois não têm liberdade) e do não-saber-ser, já que são continuamente explorados e espoliados pelo antissujeito ${ }^{8}$ e intimidados pelo destinador-manipulador (cujas funções são frequentemente sincretizadas pelo papel temático "patrão"). Por fim, são sujeitos do não-ser, pois estão frequentemente em situação ilegal, irregular ou indocumentada, a depender do ponto de vista e dos valores assumidos pelo narrador. Resumindo, os imigrantes "explorados" são sujeitos da falta, sem um objeto de valor definido e vislumbrado somente porque suas modalidades ainda estão virtualizadas. Por isso, eles são sujeitos sem um rumo definido, fadados a exercerem um fazer programado 9 que os dessemantiza por completo em sua autonomia (LANDOWSKI, 2014, p. 14-15).

De qualquer modo, o projeto de vida desses imigrantes (em suma, tornarem-se regularizados no país e ter um emprego formal e decente) tem por trás uma intencionalidade latente constitutiva de toda alteridade (LANDOWSKI, 2002, p. 41). Esse projeto do imigrante "explorado" pode um dia se realizar, a depender de um rearranjo de suas modalidades, aspecto que parece não depender somente desses sujeitos que, nesse caso, precisariam encontrar um novo destinador e adjuvante que possa auxiliá-los com a doação de novas modalidades.

Esses imigrantes também recebem uma série de sanções que em nada se comparam com as sanções dos imigrantes vistos anteriormente. Como exemplo, transcrevemos algumas palavras proferidas por uma professora de Direito Internacional, que revelam como os imigrantes explorados e, em particular, os bolivianos são vistos por parte da sociedade brasileira:

Isso é insignificante para nós. A Bolívia é insignificante em todas as perspectivas. É um pais, sim, que tem uma fronteira enorme com o Brasil. Dos nossos vizinhos, é o que tem maior fronteira terrestre, mas nós não temos nenhuma relação estratégica com a Bolívia. Nós não temos nenhum 
interesse comercial com a Bolívia. Os brasileiros não querem ir pra Bolívia. Os bolivianos que vêm de lá tentando uma vida melhor aqui não contribuem para o desenvolvimento tecnológico, cultural e social e desenvolvimentista [sic] do Brasil. Então Bolívia é um assunto menor (... $)^{10}$.

Ao contrário dos imigrantes "qualificados", os imigrantes explorados não são considerados como adjuvantes para o programa narrativo da sociedade brasileira. Nesse caso, a sanção mostra que haveria um contrato fiduciário implícito entre imigrante e sociedade brasileira que preveria o papel de auxiliar no desenvolvimento nacional em diferentes esferas (como a cultural, a social, a tecnológica ou a econômica), algo que o imigrante "explorado" não poderia nem teria condições de cumprir (diferentemente do imigrante "qualificado"). Portanto, a sanção produz a ideia de que se o imigrante é boliviano (ou qualquer outro socialmente desprestigiado), então não é bom para o Brasil.

Como não há um destaque para o saber-fazer desse imigrante, a sanção pode recair diretamente sobre sua nacionalidade, conforme o discurso anterior nos permitiu compreender. Isso nos faz pensar em como o esquema de sanção pode variar e ser ao mesmo tempo seletivo, ao se destacar elementos positivos ou negativos a serem atribuídos a um determinado grupo imigrante.

Ao lado desses dois tipos de imigrantes, veremos o aparecimento de outras duas formas da alteridade. Nem excessivamente valorizados, nem completamente desprezados, esses dois outros estilos de vida da alteridade possuem mais elementos em comum do que seria esperado, sobretudo pelo que eles utilizam dos saberes originários do espaço geográfico e social de onde vieram. No entanto, veremos também que eles possuem diferenças, principalmente em seus fazeres e práticas.

\section{O empreendedor e o artista: uma alteridade autônoma}

O terceiro tipo de imigrante se destaca por também estar às voltas com seu trabalho. No entanto, ele não é aquele que é

10 Tra n s c r i çã o realizada pelo autor. Disponível em: https:// www.youtube.com w a t ch ? v $=$ Wld D h $0 \mathrm{tNwFg}$ esperado ansiosamente pela empresa para ocupar um lugar no topo da hierarquia; tampouco é o explorado em ambientes com condições insalubres. Chamamos a esse outro imigrante pelo qualificativo "empreendedor" por conta de algumas 
características. Para depreendê-las, é preferível retomar alguns discursos que apresentam os traços mais gerais dessa forma da alteridade:

Com sorriso fácil, pele negra e brilhante, um olho sempre na cozinha e outro no caixa, Melanito Biyouha, 43, é dona do primo camaronês de restaurantes já conhecidos, como o peruano Rinconcito e o árabe Habib Ali, todos na região da cracolândia. "Abri o restaurante porque percebi que São Paulo não tinha um local que representasse a verdadeira comida do meu continente", diz a camaronesa (SENRA, 2014).

"A minha ideia é inserir todo mundo na respectiva área profissional", diz ele, advogado de formação, mas que não consegue exercer oficialmente a profissão por questões burocráticas de revalidação de diploma. "No meio do caminho encontrei músicos bons, gente que costura, cozinha. $\mathrm{E}$ aí fui criando os eventos, que geram uma renda para as pessoas que estão colocando o negócio de pé", conta. Pitchou não está sozinho. Outros indivíduos também estão ajudando a construir essa nova cena multicultural em São Paulo. Aproveitando o foco que a causa tem recebido desde que foi noticiada a maior crise global de refugiados, em 2014, e tentando se descolar da figura vitimizada muito explorada pela mídia, um grupo que sabe o que quer tem inclusive colocado a mão no bolso para fazer aquilo em que acredita e que dá prazer (MECA, 2016).

Por meio dos trechos anteriores, podemos elencar algumas características mais evidentes desse tipo de imigrante ou refugiado. Os "empreendedores" são sujeitos do querer e do saber. Mais do que isso, são sujeitos do saber-querer ("eles sabem o que querem e como chegar ao seu objetivo"). Em outras palavras, eles são sujeitos dotados de planos e objetivos a serem alcançados, apesar de em alguns casos aparecer a questão da aleatoriedade (LANDOWSKI, 2014, p. 78), ou seja, do acaso que pode beneficiá-los por conta de um reordenamento modal posterior. De qualquer maneira, eles apresentam, ao contrário do imigrante "explorado", modalidades bem estabelecidas para a execução de seus desejos e de seus planejamentos, mas não contam com o mesmo prestígio do imigrante globalizado.

Como o "empreendedor" pode começar como imigrante "explorado" que transforma a sua condição e a sua identidade, ele é um pouco como aquele que habita o imaginário social brasileiro: o imigrante bem sucedido na história, que vence na vida por meio de seu trabalho e da superação de obstáculos 
(antissujeitos). Nesse aspecto, ele é uma versão atualizada do ideal imigrante que parecia ter ficado no passado.

Os imigrantes "empreendedores" são marcados pelos temas da iniciativa e da formação acadêmica, que os aproximam dos imigrantes "qualificados". A diferença é que eles não usam, necessariamente, o seu saber sancionado positivamente por instituições de ensino para desenvolver seu comércio e suas atividades. Contudo, esse saber é destacado nas reportagens (todos os sujeitos mencionados nas reportagens possuem nível superior), o que serve igualmente para a sanção positiva sobre seu fazer e seu ser, enquanto sujeitos dotados de competência plena. Por isso, eles não necessitariam, supostamente, de qualquer forma de auxílio do poder público ou de outros destinadores ou adjuvantes.

Outro traço que define o imigrante "empreendedor" é o uso de cultura de origem para abrir negócios (restaurantes, espaços para shows etc.). Esses lugares podem se tornar espaços de admissão (LANDOWSKI, 2002, p. 65), no qual brasileiros e imigrantes podem estabelecer uma interação mais próxima do que em outros locais, como o escritório de uma grande empresa ou as oficinas de costura. Em suma, esses espaços são objetos de valor construídos pelos próprios imigrantes a partir de uma certa autonomia que eles possuem ou conquistaram.

A sanção sobre esse tipo de imigrante recaí na negação da ideia de que, sendo esse sujeito imigrante, ele é um sujeito da falta, ou seja, um sujeito carente de modalidades e de valores. O que ocorre é a negação de um esquema de implicação semelhante ao visto no imigrante "explorado" ("se é imigrante da nacionalidade X, então não serve para o Brasil"). A implicação, segundo Zilberberg (2011, p. 244-245), produz um encadeamento lógico cujo efeito é o de produzir um raciocínio esperado e, por vezes, estereotipado. Quando se nega a implicação para dar lugar à organização concessiva, gera-se um reconhecimento inesperado em relação aos sentidos cristalizados para uma determinada classe de imigrantes. Dessa maneira, com o imigrante empreendedor, temos o seguinte esquema: embora imigrante/refugiado, ele é um "empreendedor".

Para fecharmos nossa proposta de tipologia, há um outro tipo de imigrante que foge à dimensão do trabalho, ao menos sob o ponto de vista do sistema capitalista que rege boa parte das relações sociais e que, de certo modo, orienta os temas das 
reportagens mencionadas até esta parte. Trata-se, nesse caso, de um sujeito que usa também o conhecimento de sua cultura de origem, mas sem ter os recursos do imigrante "empreendedor". Esse é o caso do imigrante que podemos chamar de "artista".

A partir de alguns poucos trechos selecionados, podemos elencar alguns de seus traços recorrentes:

Fundadores do Vizyon, Watsen Joseph, 31, e Dieufaite Joseph, 27, tiveram bandas no Haiti. No Brasil, são eletricista e pedreiro, respectivamente. Mas, a exemplo dos bolivianos e suas onipresentes flautinhas, querem sobreviver só da música e difundir a cultura haitiana no Brasil.

O estilo musical mais conhecido do país, o compas (pronuncia-se com-pá), também aparece nesse começo de cena cultural haitiana do Brasil. "É pra dançar agarradinho, a dois, como vocês fazem com o forró", afirma Louides Charles, 36, tecladista e líder da banda Satellite Musique, fundada em janeiro de 2014. Os onze membros do grupo se conheceram em São Paulo (GRAGNANI, 2014).

Assim como os imigrantes "empreendedores", o imigrante "artista" usa seu conhecimento para criar seu próprio objeto. Ele se vale de sua própria criatividade e de seu próprio corpo para isso. Uma outra diferença está no fato de que os artistas têm como competência seu saber estético.

Trabalhando com o já dado de sua cultura, o imigrante "artista" produz discursos mesclados em sua língua e na língua da sociedade receptora. Ele, assim, traduz, em parte, os temas e as figuras de seu universo originário de sentidos para uma nova realidade de significações, como é o caso dos músicos haitianos, apesar de ainda apresentarem um português pouco proficiente, como apontado pela reportagem.

Apesar de em alguns pontos os imigrantes "artistas" se aproximarem dos imigrantes "empreendedores", seu fazer e a construção de seu objeto de valor os diferenciam. Assim, enquanto há uma troca comercial no espaço do restaurante, a troca que envolve o imigrante "artista" é mais da ordem do inefável, realizado em uma esfera distinta, com uma intencionalidade diversa: a do espaço público em sua busca pelo reconhecimento de sua arte (ou seja, de sua prática) pelo público que ele pode formar (o que não implica na falta de desejo de obter também algum benefício financeiro para poder viver de modo tranquilo). Nesse caso, a troca entre artista e público não leva à perda de um objeto de valor de um dos sujeitos para o 
outro, como é o caso da troca comercial, em que há uma perda mútua (o dinheiro de um que adquire o produto do outro ${ }^{11}$.

Dessa forma, a partir dos elementos depreendidos na análise, podemos começar a organizar as características dos tipos de imigrantes apresentados anteriormente:

\begin{tabular}{|l|l|l|l|}
\hline \multicolumn{1}{|c|}{$\begin{array}{c}\text { Tipo de } \\
\text { imigrante }\end{array}$} & \multicolumn{1}{|c|}{ Papéis temáticos } & Estilo de vida & \multicolumn{1}{c|}{$\begin{array}{c}\text { Sanção da sociedade } \\
\text { brasileira }\end{array}$} \\
\hline $\begin{array}{l}\text { Imigrante } \\
\text { qualificado }\end{array}$ & $\begin{array}{l}\text { Cidadão globalizado; } \\
\text { executivo; técnico }\end{array}$ & $\begin{array}{l}\text { Alteridade } \\
\text { assimilada }\end{array}$ & $\begin{array}{l}\text { Valorização do saber-ser e do } \\
\text { saber-fazer }\end{array}$ \\
\hline $\begin{array}{l}\text { Imigrante } \\
\text { explorado }\end{array}$ & $\begin{array}{l}\text { Trabalhador sem } \\
\text { formação; explorado }\end{array}$ & $\begin{array}{l}\text { Alteridade } \\
\text { segregada }\end{array}$ & $\begin{array}{l}\text { Desvalorização de cultura de } \\
\text { origem e de seu trabalho }\end{array}$ \\
\hline $\begin{array}{l}\text { Imigrante } \\
\text { empreendedor }\end{array}$ & $\begin{array}{l}\text { Dono de restaurante; } \\
\text { empreendedor } \\
\text { cultural }\end{array}$ & $\begin{array}{l}\text { Alteridade } \\
\text { admitida }\end{array}$ & $\begin{array}{l}\text { Valorização de sua cultura de } \\
\text { origem e de sua iniciativa }\end{array}$ \\
\hline Imigrante artista & Músico & $\begin{array}{l}\text { Alteridade } \\
\text { admitida }\end{array}$ & $\begin{array}{l}\text { Valorização de sua cultura de } \\
\text { origem e de sua iniciativa }\end{array}$ \\
\hline
\end{tabular}

\footnotetext{
11 No caso da troca comercial, trata-se de uma relação que envolve dois objetos, pois ambos os sujeitos envolvidos se disjungem de um objeto de valor (o consumidor, do dinheiro; o vendedor, do objeto vendido) para entrarem em conjunção com o objeto de valor desejado (o consumidor, o objeto vendido; o vendedor, o dinheiro). No caso da troca que existe entre artista e público, o objeto é único (a canção, o quadro). Nesse caso, o artista não necessariamente entre em disjunção com seu objeto enquanto o público entra em conjunção. Para maiores e s c la r e c i m e n t o s sobre essas relações, remetemos a GREIMAS, A. J. Sobre o sentido II. São Paulo: EDUSP/Nankim, 2014, pp. 44-55.

${ }^{12}$ Além disso, recorrer às significações elencadas em outras análises a partir de objetos distintos nos mostra a eficiência do modelo semiótico de análise, pois uma mesma significação pode ser encontrada em outros objetos de pesquisa.
}

Para tentarmos explicar um pouco melhor como a sanção recai de modo distinto sobre os diferentes tipos de alteridade depreendidos na análise, recorremos à proposta de Floch $(2009$, p. $144 ; 149)$ sobre os diferentes valores que ele produziu a partir de suas análises de propagandas de automóveis. O que pode parecer inicialmente algo estranho, pois pessoas não são carros, foi o meio que encontramos para compreender como cada grupo imigrante possui um determinado valor pelo ponto de vista da sociedade ${ }^{12}$ :

Valores utilitários
(valorização prática)
"empreendedor"


A valorização prática define o imigrante "empreendedor", sobretudo porque sua figura mobiliza o tema do sujeito bem-sucedido que conquistou o que possui por conta de sua praticidade e do seu próprio fazer. Em oposição a esse sujeitoimigrante, teríamos o trabalhador "qualificado" que, por ser um ideal a ser alcançado pela sociedade de recepção, mobilizaria valorização utópica que representa o desejo de ser igual a eles: competentes, profissionais, globalizados e com saberes ainda não encontrados na sociedade em questão. No eixo dos subcontrários, temos a valorização crítica, que se liga ao imigrante "explorado", enquanto uma negação da valorização utópica e uma representação do que a sociedade não quer para si mesma. Assim, sua presença é desvalorizada na proporção inversa à valorização do imigrante "qualificado". Por fim, os imigrantes "artistas" mobilizam valorizações lúdicas pelo seu fazer e pela sua prática, mais próxima ao universo artístico do que da valorização prática dos imigrantes "empreendedores".

Dessa maneira, a valorização utópica pode explicar por que o imigrante "qualificado" é a alteridade assimilada: é esse o estrangeiro que a sociedade deseja, a ponto de querer integrá-lo para que suas ações e auxílios possam tornar o país melhor (tanto que ao menos dois disseram que querem morar permanentemente no Brasil). A valorização crítica é responsável por tornar o imigrante "explorado" uma presença indesejável e, por isso, ele permanece como uma alteridade segregada (do mercado formal de trabalho, da vida social da cidade e do reconhecimento de seus direitos). Já a valorização prática do modo aparentemente objetivo com o qual o imigrante "empreendedor" e o imigrante "artista" agem em benefício próprio (e de outros de modo secundário) com seu estabelecimento comercial ou com sua arte os tornam uma alteridade admitida, ou seja, com a permanência de seus traços culturais de origem que são valorizados pela sociedade.

\section{Conclusões}

Por meio dos discursos selecionados, vimos neste trabalho que o imigrante não é uno. Pelo contrário, há diferentes tipos de imigrantes que podem ser encaixados em diferentes estilos de vida a partir de suas caraterísticas, elementos que estão 
também na base das diferentes valorizações produzidas pela sociedade de recepção.

Entendemos que a sanção que se aplica aos imigrantes varia conforme as conveniências da sociedade de recepção respaldadas por esses valores. Em outras palavras, são as diferentes valorizações da alteridade que determinam como ela será construída: assimilada, admitida ou segregada. É por isso que um imigrante "explorado" não tem seu fazer reconhecido e valorado, nem obterá o mesmo reconhecimento de um imigrante "qualificado", por mais que se esforce em realizar um bom trabalho.

A questão de fundo que se discute, a partir dos diferentes tipos de imigrantes que depreendemos na análise, é o tipo de contrato que a sociedade visa a estabelecer com os imigrantes. Assim, estrangeiros que podem supostamente acrescentar algo à sociedade, principalmente pelo viés econômico, são amplamente aceitos e contam até com uma política específica para atrai-los, uma vez que o estilo de vida desses sujeitos é o ideal a ser alcançado pela sociedade brasileira. Em relação ao imigrante "empreendedor", há uma postura de aceitação (mas não de incentivo para entrarem no país) pelo que podem contribuir com o aumento da diversidade cultural e com a iniciativa quase sempre individual para se alcançar melhores condições de vida, em uma perspectiva igualmente econômica. Já o imigrante "explorado" mantém-se confinado ao seu ambiente de trabalho insalubre e o máximo que a sociedade e o Estado fazem por ele é tentar desbaratar as oficinas ilegais, mas sem interferir na questão econômica, pois o que eles recebem faz parte da cadeia de produção que gera consideráveis lucros aos grandes magazines de roupa.

Como dissemos no começo do trabalho, os discursos examinados servem também para pensarmos em como o imigrante e o refugiado são representados em apenas uma faceta de seus simulacros. Nesse sentido, os tipos de alteridade que analisamos podem servir como ponto de partida para refletirmos sobre como os meios de comunicação possuem uma prática discursiva voltada para o "congelamento" das identidades, enquanto uma parada necessária para tornar o outro inteligível e, assim, contribuir para a construção e a cristalização de estereótipos que orientam a sociedade em seu ato de reconhecimento e de entendimento do outro. Mais 
do que isso, os meios de comunicação podem determinar comportamentos e hábitos, não somente ligados à alteridade, mas também de uma maneira mais ampla, tal como parece indicar o seguinte trecho extraído do texto de Landowski:

Porque, mesmo que todo mundo seja em princípio "sujeito" do mesmo modo, cada um se apresenta na realidade, tanto para outrem como para si mesmo, como pertencente a "sua" categoria sócio-profissional, a "seu" meio étnico ou cultural, a "seu" grupo linguístico ou confessional - e, é claro, além do mais, a sua faixa etária, a sua geração, a seu sexo, e assim por diante -, de modo que, em definitivo, na medida em que esses diferentes critérios de referência tendem a superpor-se uns aos outros e, na maioria das vezes, a reforçar mutuamente seus efeitos, alguns membros da comunidade chegam muito naturalmente a passar por "um pouco mais" sujeito que outros - como se, ao acumularem as marcas sociais convencionalmente consideradas mais positivas, eles encarnassem por si sós o tipo mais acabado do grupo considerado, ao passo que os outros não passariam de imagens falhas, ou mesmo em negativo, desse grupo (LANDOWSKI, 2002, p. 32).

Assim, mais do que falar sobre o outro, parece ser necessário questionar também os nossos próprios procedimentos de representação do outro. No caso, procedimentos que se tornaram mais ou menos padronizados e que, se não são completamente considerados positivos, não deixam de ser quase "naturalizados" para se manter um distanciamento "seguro" em relação à alteridade. Esse pode ser um primeiro passo para uma abertura maior em relação ao outro, não apenas para reconhecê-lo e aceitá-lo, mas principalmente para aprender com eles.

\section{REFERÊNCIAS}

FLOCH, Jean-Marie. Sémiotique, Marketing et Communication. Paris: PUF, 2009.

GRAGNANI, J. Imigrantes fundam bandas e constroem cena cultural haitiana. Disponível em: <http://www1.folha.uol.com. br/ilustrada/2014/09/1511002-imigrantes-fundam-bandas-econstroem-cena-cultural-haitiana.shtml>. Acesso em 12 de novembro de 2016.

GREIMAS, A.J. Sobre o sentido II - ensaios semióticos. Tradução de Dilson Ferreira da Cruz. São Paulo: EDUSP/Nankim, 2014. 
GREIMAS, A.J.; COURTÈS, J. Dicionário de semiótica. Tradução de Alceu Dias Lima et al. São Paulo: Contexto, 2008.

KOMETANI, P. G1, 94,6\% dos vistos de trabalho são para estrangeiros qualificados, diz governo. 07 de fevereiro de 2013. Disponível em: <http://g1.globo.com/concursos-eemprego/noticia/2013/02/946-dos-vistos-de-trabalho-saopara-estrangeiros-qualificados-diz-governo.html $>$. Acesso em 15 de abril de 2015.

LANDOWSKI, E. Interações arriscadas. Tradução de Luiza Helena O. da Silva. São Paulo: Estação das Letras e Cores, 2014. LANDOWSKI, E. Presenças do outro. Tradução de Mary Amazonas Leite de Barros. São Paulo: Perspectiva, 2002.

MECA. Quem são os refugiados que estão mudando a cena cultural deSP. Disponível em: <http://meca.love/post/refugeesocial-club>. Acesso em 22 de setembro de 2015.

ROLLI, C. Fiscais autuam fábrica de colete do Censo. (Folha de São Paulo, 20 de outubro de 2010). Caderno Mercado, página B6. Disponível em: <http://www1.folha.uol.com.br/fsp/mercado/ me2010201020.htm>. Acesso em 09 de novembro de 2013.

ROLLI, C.; FERNANDES, F. Até 1.500 bolivianos chegam por mês. Folha de São Paulo, 16 de dezembro de 2007a. Caderno Dinheiro, página B19. Disponível em: <http://www1.folha. uol.com.br/fsp/dinheiro/fi1612200709.htm>. Acesso em 09 de novembro de 2013.

ROLLI, C.; FERNANDES, F. Mão de obra degradante migra para o interior de SP. Folha de São Paulo, 30 de setembro de 2007b. Caderno Dinheiro, página B5. Disponível em: <http:// www1.folha.uol.com.br/fsp/dinheiro/fi3009200705.htm>. Acesso em 09 de novembro de 2013.

SENRA, R. FOLHA de S. Paulo. Depois dos peruanos, restaurantes populares africanos ganham espaço no centro de SP. Disponível em: <http://www1.folha.uol.com.br/ saopaulo/2014/01/1395740-depois-dos-peruanos-restaurantespopulares-africanos-ganham-espaco-no-centro-de-sp.shtml>. Acesso em 25 mar. 2014.

ZILBERBERG, C. Elementos de semiótica tensiva. Tradução de Ivã Carlos Lopes, Luiz Tatit, Waldir Beividas. São Paulo: Ateliê Editorial, 2011. 


\section{Abstract \\ Lifestyles of immigrants and refugees in the media}

Among the reports on contemporary immigration to Brazil, we can distinguish different foreign groups from the work they do: one that shows the so-called "skilled" foreign workers who come to occupy management positions in multinationals; Another that refers to those who work in commerce, administering their own businesses; A third that presents the immigrants "without qualification"; and, lastly, a last one that can be seen as the "artist". If we start from the premise that the thematic role of the immigrant is that of a subject of work, we observe how these senses linked to the universe of work are complemented by others that mix social class and national origin. Besides these questions, we wish to observe how this division of groups is positively and negatively valued as a way of trying to understand how Brazilian society sanctions different immigrant groups and their different social functions at work. Finally, we will see how the images of the country are constructed, a recurring topic in these reports. In order to reach our objectives, we have recourse to the postulates of discursive semiotics, especially the proposals of the sociossemiotic.

Keywords: Lifestyles. Immigration. Sanction. Values. 